\title{
Biting midges, no-see-ums Culicoides spp. (Insecta: Diptera: Ceratopogonidae) ${ }^{1}$
}

\section{Roxanne Connelly ${ }^{2}$}

\section{Introduction}

Biting midges can be a nuisance to campers, fishermen, hunters, hikers, gardeners, and others who spend time outdoors during early morning and evenings, and even during the daytime on cloudy days when winds are calm. They will readily bite humans; the bites are irritating, painful, and can cause long-lasting painful lesions for some people.

A common observation upon experiencing a bite from this insect is that something is biting, but the person suffering can not see what it is. Biting midges are sometimes incorrectly referred to as sand flies. Sand flies are insects that belong to a different biological group and should not be confused with the biting midges.
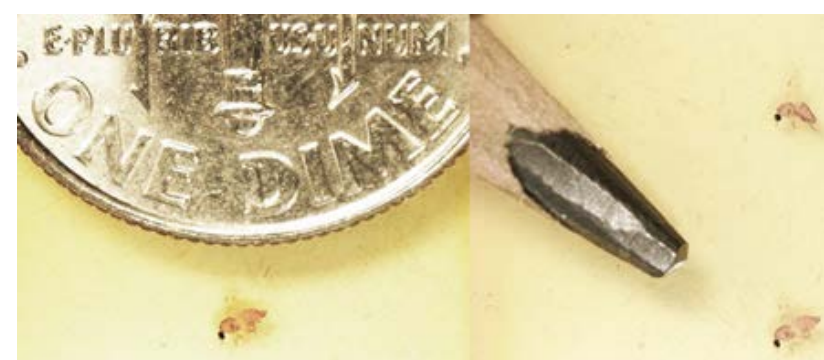

Figure 1. Culicoides furens shown next to a U.S. dime and pencil point to demonstrate the relative size of this adult biting midge species. Credits: Roxanne Connelly, Florida Medical Entomology Laboratory, University of Florida.

\section{Distribution}

There are over 4,000 species of biting midges in the Ceratopogonidae family, and over 1,000 in just one genus, Culicoides. The distribution of midges in the genus Culicoides is world-wide; 47 species are known to occur in Florida. Species belonging to the genus Leptoconops occur in the tropics, sub-tropics, the Caribbean, and some coastal areas of southeast Florida.

The natural habitats of biting midges vary by species. Areas with substantial salt marsh habitat are major producers of many biting midge species. Additional sources for some species, like the bluetongue virus vector Culicoides sonorensis Wirth and Jones, include highly organic soil that is wet but not underwater such as those found with high manure loads in swine-, sheep- and cattle-farming operations. These insects do not establish inside homes, apartments, or inside humans or other animals.

\section{Description}

Immature Stages: The eggs can be cigar-, banana-, or sausage-shaped and approximately $0.25 \mathrm{~mm}$ long. They are white when first laid but later turn brown or black. The eggs are laid on moist soil and cannot withstand drying out. Some species can lay up to 450 eggs per batch and as many as seven batches in a lifespan. Eggs typically hatch within two to 10 days of being laid; time to hatch is dependent on the species and temperatures.

1. This document is EENY 349, one of a series of the Entomology and Nematology Department, Florida Cooperative Extension Service, Institute of Food and Agricultural Sciences, University of Florida. Original publication date May 2005. Revised April 2013. Visit the EDIS website at http://edis.ifas.ufl.edu.

2. C. Roxanne Connelly, associate professor, Florida Medical Entomology Laboratory, Cooperative Extension Service, Institute of Food and Agricultural Sciences, University of Florida, Vero Beach, FL 32962. 
The larvae are worm-like, creamy white, and approximately 2 to $5 \mathrm{~mm}$ long. Larvae develop through four instars; the first instar larvae possess a functional spine-bearing proleg. Pupal color can be pale yellow to light brown to dark brown. They are 2 to $5 \mathrm{~mm}$ in length with an unsegmented cephalothorax that has a pair of respiratory horns that may bear spines or wrinkles. During this stage, the insects possess a spiny integument which can be used to identify the fly to species level.

Adults: The adult no-see-ums are gray and less than $1 / 8$ inch long. The two wings possess dense hairs and give rise to pigmentation patterns. These wing patterns are used by biologists to identify species. The large compound eyes are more or less contiguous above the bases of the 15-segmented antennae. The pedicel of the males' antennae houses the Johnston's organ. The mouthparts are well-developed with cutting teeth on elongated mandibles in the proboscis, adapted for blood-sucking in females but not in males. The thorax extends slightly over the head, and the abdomen is nine-segmented and tapered at the end.

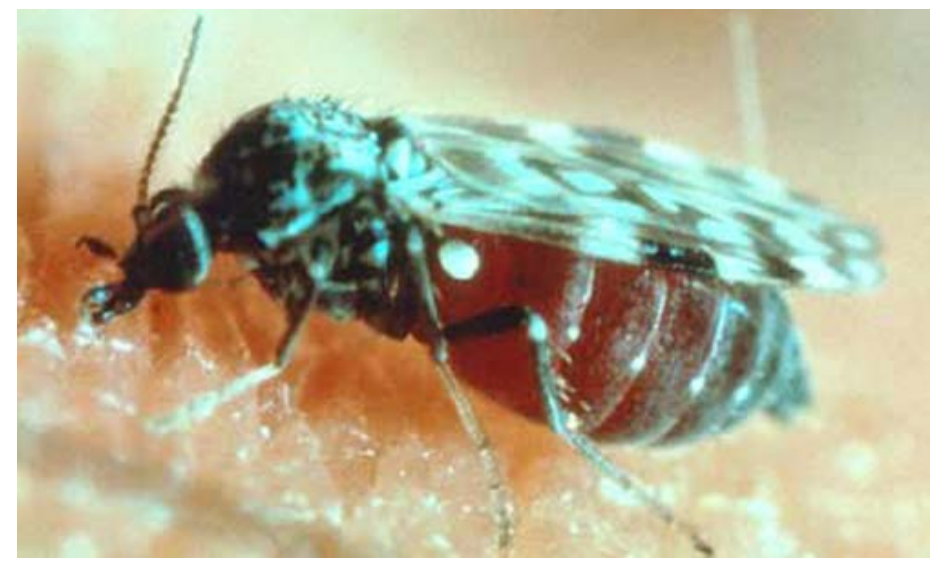

Figure 2. Adult biting midge, Culicoides sonorensis Wirth and Jones, showing blood-filled abdomen and the characteristic wings patterns used for species identification.

Credits: EdT. Schmidtmann, USDA/ARS

\section{Life Cycle}

Adults: Biting midges are holometabolous, progressing from egg to larva to pupa, and finally to the adult stage. The complete cycle can occur in two to six weeks, but is dependent on the species and environmental conditions. The adults are most abundant near productive breeding sites, but will disperse to mate and to feed. The mean distance for female flight is $2 \mathrm{~km}$, less than half of that distance for males.

Male Culicoides typically emerge before the females and are ready to mate when the female emerges from the pupal stage. Mating typically occurs in flight when females fly into swarms of males and the insects are oriented end to end with the ventral parts of the genitalia in contact. Some species mate without swarming; instead, the males go to hosts where the female is likely to feed on blood; mating occurs when she finishes feeding.

Eggs: Males and females feed on nectar, but the females require blood for their eggs to mature. The females will blood-feed primarily around dawn and dusk; however, there are some species that prefer to feed during the day. Some species are autogenous and therefore may produce the first batch of viable eggs without a blood meal using reserves stored from the larval period; blood meals are required for subsequent batches of eggs.

The number of eggs produced varies among species and size of bloodmeal. For example, Culicoides furens (Poey) can lay 50 to 110 eggs per bloodmeal, and C. mississippiensis Hoffman, 25 to 50 eggs per bloodmeal. The adults can live two to seven weeks in a laboratory setting, but only a few weeks under natural conditions.

Larvae: Larvae require water, air and food and are not strictly aquatic or terrestrial. They cannot develop without moisture. The larvae are present in and around salt-marsh and mangrove swamps, on shores of streams and ponds, and in muddy substrates. They feed on small organisms. Most species cannot exist more than a few inches below the air-water interface.

In the tropics, the larval habitat of many species is in rotting fruit, bromeliads, and other water-holding plants. Other larval habitats include mud, sand, and debris at edges of ponds, lakes and springs, tree holes, and slime-covered bark. The larval stage can last from two weeks to a year, depending on the species, temperatures, and geographic area.

While some larvae can develop in wet manure-contaminated areas (Mullen 2002), they do not develop inside the animal. The larvae also do not develop inside humans or other animals.

Pupae: The pupal stage typically lasts $\sim$ two to three days.

\section{Medical Significance}

In the U.S., the biting midges are primarily a nuisance and the major medical issue associated with Culicoides is allergic reactions to the bites. However, like other blood feeding Diptera, Culicoides species are vectors of pathogens that can cause disease in humans and animals. In Central and South America, western and central Africa, and some Caribbean 
islands, biting midges are the vectors of filarial worms in the genus Mansonella. These parasites cause infection in humans that produces dermatitis and skin lesions because the adult worms are located in the skin.

Biting midges, primarily the species Culicoides sonorensis, are responsible for transmission of bluetongue virus to sheep and cattle in the U.S. Bluetongue is a serious disease of ruminants. Bluetongue viruses are found world-wide and are transmitted by different Culicoides species in different regions. Many countries that are bluetongue-free prohibit the movement of livestock from bluetongue endemic regions. The annual economic damage in lost trade is in the millions of dollars.

Other animal disease causing pathogens transmitted by the bite of infected biting midges include African Horsesickness virus in equines that is confined primarily to Africa and Epizootic Hemorrhagic Disease virus in ruminants found in North America and principally having lethal effects on deer. Some equines experience allergic reactions to the bites, resulting in equine allergic dermatitis, affecting the withers, mane, tail and ears of the animal.

\section{Management and Prevention}

Historically, management methods included diking and drainage of marshlands to reduce the habitats used by the immature stages. The insecticide DDT was used to target the adult stage. Currently, larval habitats are not targeted in control efforts because of the extensive amount of area that the habitats may cover, some negative environmental impacts resulting from changing water flow patterns of large areas, and the spotty spatial distribution of larvae within a given habitat.

Applications of insecticides targeting the adult stage are not efficient. While this type of application may kill biting midges active on a given night, they are continually dispersing from the larval habitat and entering areas of human activity. It would require insecticide applications on a daily basis in some areas, and this is not efficient or environmentally sound. Many government agencies that provide mosquito control services receive complaint calls about biting midges. However, most of the programs are not mandated or allowed to respond by providing control measures.

On a large scale, removal trapping is conducted using $\mathrm{CO}^{2}$ as an attractant to lure the biting midges to an insecticidetreated target where they are killed. Research from the IFAS Florida Medical Entomology Laboratory showed that biting midge populations were reduced in test areas of Vero Beach and Boynton Beach, FL, and Castaway Cay, Bahamas. This method of control is more appropriate for islands and specific inland areas where pest control personnel can make a long term commitment to this technique.

Homeowners can install proper screening for windows and patios to prevent no-see-ums from entering residences and outdoor areas used for leisure and entertaining. Most biting midges can pass through 16-mesh insect wire screen and netting, so a smaller mesh size is required. The small mesh size does limit air flow through the screens. Additionally, because no-see-ums are so small and are weak fliers, ceiling and window fans can be used at high speeds to keep no-seeums out of small areas.

Repellents containing DEET (N,N-diethyl-meta-toluamide) typically used as mosquito repellents are also labeled for use against no-see-ums and can be applied prior to exposure to the biting midges. It is important that the directions for application that are printed on the label are followed for any product used as a repellent.

Coastal areas provide primary habitat for biting midges. Tourists and potential home and land owners can consult local maps prior to visiting or purchasing property in coastal areas, to determine the proximity to biting midge producing areas. It is prudent to research the area of geographic interest prior to making decisions that can lead to an unpleasant vacation or unhappy homeowners. Knowing the breeding habitats, and that large scale control operations are not feasible, one can be prepared with repellents or make decisions to build, or visit, elsewhere.

\section{Selected References}

Blanton FS, Wirth WW. 1979. The sand flies (Culicoides) of Florida (Diptera: Ceratopogonidae). Arthropods of Florida and Neighboring Land Areas; Volume 10. Florida Department of Agriculture and Consumer Services. Gainesville, FL. 204 pp.

Day, JF, Duxbury, CG, Glasscock, S and Paganessi, JE. 2001. Removal trapping for the control of coastal biting midge populations. Technical Bulletin of the Florida Mosquito Control Association. 4th Workshop on Salt Marsh Management and Research. Florida Mosquito Control Association, Ft. Myers, FL. 3: 15-16.

Eldridge, BF and Edman, JD, Eds. 2000. Medical Entomology: A Textbook on Public Health and Veterinary Problems 
Caused by Arthropods. Kluwer Academic Publishers, Dordrecht, The Netherlands.

Foote RH, Pratt HD. 1954. The Culicoides of the eastern United States (Diptera, Heleidae). Public Health Monograph No. 18. Publication No. 296. U. S. Department of Health, Education and Welfare, Public Health Service. 53

pp.

Holbrook FR. 1996. Biting midges and the agents they transmit. In Beaty BJ, Marquardt WC (Eds), The Biology of Disease Vectors. University Press of Colorado, Niwot, CO. p. 110-116.

Mullen G. Biting midges (Ceratopogonidae). In Mullen G, Durden L (Eds). 2002. Medical and Veterinary Entomology. Elsevier Science, San Diego, CA. p. 163-183.

Rutledge CR, Day JF. (2002). Mosquito Repellents. EDIS. University of Florida/IFAS. http://edis.ifas.ufl.edu/IN419 (11 May 2005). 